\title{
The Effect of Abelmoschus esculentus in Alloxan- Induced Diabetic Wistar Rat
}

\author{
Ben-Chioma, A.E. ${ }^{1}$, Tamuno-Emine, D.G. ${ }^{2}$, Dan, D.B. ${ }^{3}$ \\ Department of Medical Laboratory Sciences, Rivers State University of Science and Technology, Nkpolu, Port Harcourt, Nigeria
}

\begin{abstract}
The anti-hyperglycaemic activity of Abelmoschus esculentus fruits in alloxan-induced diabetic wistar rats was investigated. The animals were grouped into five (5); A, B, C, D, and Egroups. Diabetic Mellitus was induced in groups B-E by single intravenous injection of alloxan, 65mg/kg body weight. Group A served as normal control (non-diabetic). Group C and D diabetic rats were administered with aqueous extracts and dried powdered form of Abelmoschus esculentus fruit respectively. Group E was administered with standard anti-diabetic drug [glibenclamide]. Treatment was for 14 days. Blood samples were taken and the fasting blood glucose levels measured at days 3,7, and14. The aqueous and dried powdered form of Abelmoschus esculentus significantly decreased (p<0.05) blood glucose levels of the animals. The results support the therapeutic use of Abelmoschus esculentus as an anti diabetic plant.
\end{abstract}

Keywords: Anti-hyperglycaemic, Abelmoschus esculentus, Alloxan, Glibenclamide

\section{Introduction}

Diabetes mellitus (DM) can be described as the increase of glucose in the blood. It is a metabolic disorder of multiple causes characterised by chronic hyperglycaemia, absolute or relative lack of insulin and late complications due to disturbance of carbohydrate, fat, and protein metabolism (WHO, 2011). It is a condition which results when the pancreas no longer produces enough insulin or when the cells stop responding to the insulin produced leading to impaired glucose uptake into the cells of the body. The chronic hyperglycaemia of diabetes is associated with longterm damage, dysfunction and failure of various organs, especially the eyes, kidneys, nerves, heart and blood vessels. Under this condition of chronic hyperglycaemia, there is a non-enzymatic irreversible attachment of glucose molecules to N-terminal of haemoglobin molecules in the red blood cells, a process called glycation.

DM is a potentially morbid condition with high prevalence. Epidemiological studies in 2010 show that about $2.8 \%$ of the global population, an estimated 285 million people had diabetes (Beretta, 2012). The figure is believed to increase by the year 2035 and in sub-Saharan Africa; Nigeria will be leading in the figures. Due to this high prevalence and psychological state, diabetes is a major medical concern. The disease remains incurable and can only be controlled with drugs, and in some cases exercise and dietary recommendations (Macedoet al., 2002)

In developing countries including Nigeria, most diabetic patients find it increasingly difficult to manage hyperglycaemic conditions, the major cause of the complications of DM, not only because of the high cost of the synthetic ant-diabetic drugs that may even be more devastating than the disease itself and can lead to death (Ichinose et al., 2009). The management of DM without any side effects is still a challenge to the medical system as the treatment of DM is relatively limited by significant side effects. There is growing interest however in the use of natural health products as an alternative approach to current medications. Plant sources have become a target to explore new drugs and in searching a biologically active compound
(Yehet al., 2003). Ethnopharmacological surveys indicate that more than 1200 plants are used worldwide in traditional medicine for their alleged hypoglycaemic activity (Berreta, 2012).

Drug and chemical induced diabetes are commonly obtained from the use ofan experimental animal model of diabetes mellitus. Alloxan induced DM appear to be the most reliable and easily reproducible method of inducing DM in experimental animals (Rees and Alcolado, 2005). Alloxan, a $\beta$-cytotoxin, induces diabetes by damaging the $\beta$-cells of islets of langerhans of the pancreas resulting in decrease endogenous insulin production and release, thereby causing hyperglycaemia within a short period.

The investigation of anti-diabetic agents of plant origin which are used in traditional medicine is thus of great significance. Some plant products used in traditional medicine have proven their potential as ant-diabetic agents and are from edible plants. This has added more interest in their study because of the duality of their role, as food and as medicine for the management of DM and other ailments. Some medicinal plants have been implicated in the management and control of hyperglycaemia. Available literature indicates that more than 800 plant species have hypoglycaemic activities (Rajaopal and Sakrikala, 2008).

Abelmoschus esculentus (hereafter referred to as $A$. esculentus) is known as lady's finger in many Englishspeaking countries. Okra, as it is known in Nigeria is a flowering plant in the mallow family (Chopra et al., 1996), valued for it's edible green seed pods is an important vegetable and widely distributed from Africa to Asia, Southern Europe etc. (Khomsug, 2010). A. esculentus is an annual herb that is coarse, erect and has branches $0.6-1.5 \mathrm{~m}$ high in length and with a long petioled leaves, orbicularoviate that has about $25 \mathrm{~cm}$ or less in length. The fruit of this plant gives nutritional benefits like protein, niacin, riboflavin, phosphorus, zinc, copper, potassium, vitamins $\mathrm{A}$, $\mathrm{B}, \mathrm{C}$ and $\mathrm{K}$, thiamine, magnesium, folate, calcium and manganese.

\section{Volume 4 Issue 11, November 2015}




\section{International Journal of Science and Research (IJSR) \\ ISSN (Online): 2319-7064}

Index Copernicus Value (2013): 6.14 | Impact Factor (2014): 5.611

The superior fibre found in okra helps to stabilize the blood sugar by curbing the rate at which sugar is absorbed from the intestinal tract. Okra's mucilage binds also cholesterol and bile acids carrying toxins dumped into it by filtering liver. Okra helps lubricate the large intestines due to its bulk laxative qualities. The okra fibre absorbs water and ensures bulk in stools, which helps prevent and improve constipation. Previous literatures have reported few studies on the lipid lowering properties of okra in blood. This present study is to investigate antidiabetic properties of Abelmoschus esculentus as a model to see how the okra seed, which is widely eaten for its nutritional benefits can also be used as medicinal alternative in the treatment of diabetes. Also, the people who live in the villages have little knowledge of the many medicinal properties of the plant in their environment while the city dwellers for time rely heavily on conventional drugs, which are expensive and with side effects.

\section{Justification for the Study}

The quest for dietary based remedies for DM necessitates investigation of available and cheap edible natural foods of plant origin with fewer side effects in experimental animals. The aim of this study therefore was to evaluate the effects of A. esculentus extracts on the blood glucose levels of alloxaninduced hyperglycaemic rats as a new approach or alternative in the treatment of diabetes as its medicinal potential is yet to be fully exploited

\section{Materials and Methods}

\section{Experimental Animals}

Thirty male wistar albino rats weighing between $150-350 \mathrm{~g}$ were obtained from the animal house of college of Health Sciences, University of Port Harcourt. The animals were placed in standard ventilated cages and maintained under standard laboratory conditions with free access to food and water and studies were carried out in strict guidelines for the care of laboratory animal.

\section{Okra Collection and Identification}

Fresh fruits of $A$. esculentus were bought from Mile 3 Market in Port Harcourt, Nigeria on the $2^{\text {nd }}$ of June 2014. A curator in the Department of Applied and Environmental Biology, Rivers State University of Science and Technology did botanical identification.

\section{Preparation of Aqueous extract}

Fresh okra was washed and both ends were cut off and placed in a clean drinking water overnight. The fruits were removed and the aqueous extracts, put into water bottles. The extracts were prepared fresh each day.

\section{Dried Powder Preparation}

After washing, some of the fruits were sundried for days and grinded into powder and stored into airtight containers for use throughout the study.

\section{Chemicals}

Alloxan monohydrate and other chemicals used in this work were of good grades and were purchased from Ekoistic Laboratories, Port Harcourt, Nigeria.

\section{Toxicity Studies}

There was no toxicity observed in the aqueous extracts of $A$. esculentus up to $200 \mathrm{mg} / \mathrm{kg}$ body weight. Toxicity was observed in the rats using alloxan monohydrate at a concentration range of $55-80 \mathrm{mg} / \mathrm{kg}$-body weight dissolved in normal saline. Each of the animals was injected with a specific concentration and observed for mortality within 7 days. Within the 7 day period, the animals that received $80 \mathrm{mg} / \mathrm{kg}$ of alloxan died due to hypoglycaemia while those that received $55-60 \mathrm{mg} / \mathrm{kg}$ of alloxan did not attain the desired hyperglycaemic level but the animals that received alloxan at $65 \mathrm{mg} / \mathrm{kg}$ body weight had a pronounced hyperglycaemia, survived over the period.

\section{Induction of Diabetes Using Alloxan in Rats/Experimental Design}

Healthy animals were fasted overnight. At the end of the of the fasting duration, they were weighed and the baseline glucose level was determined with blood drawn from the tail vein usingAccuchek Active glucometer with slot number 995.

Twenty -five rats were divided into five groups of rats labelled A-E. Group A served as normal control (nondiabetic). Groups B-E were induced by injecting $65 \mathrm{mg} / \mathrm{kg}$ body weight I.V with alloxan monohydrate prepared by dissolving the equivalent milligrams of alloxan in $0.5 \mathrm{ml}$ of normal saline in a dark environment to preserve the potency of the photo labile diabetogen. Group B served as diabetic control while group $\mathrm{C}$ was treated with aqueous extract $(100 \mathrm{mg} / \mathrm{kg})$ of A.esculentus. Group D was treated with dried okra powder $(100 \mathrm{mg} / \mathrm{kg})$ dissolved in distilled water and clean drinking water. Group E served as standard drug group treated with glibenclamide $(5 \mathrm{mg} / \mathrm{kg})$. All treatments were given orally for 14 days. To forestall death of the rats due to hypoglycaemia, the rats received $10 \%$ dextrose water after $6 \mathrm{hrs}$ post alloxan induction. Induction of diabetes was verified after $72 \mathrm{hrs}$ by measuring blood glucose levelsusingAccuchek Active glucometer with slot number 995. Animals were allowed 7 days for the stabilization of blood glucose level and animals having a blood glucose level of up to $250 \mathrm{mg} / \mathrm{dl}$ or above were considered diabetic. Estimation of blood glucose was done every week. On the $14^{\text {th }}$ day, the animals were anaesthezied with chloroform pulled over their face and blood sample collected in the fluoride oxalate bottle for the estimation of blood glucose determined using the glucose oxidase method after plasma separation by centrifugation at $1500 \mathrm{rpm}$ for 3 minutes.

\section{Statistical Analysis}

All statistical analysis was done using statistical package for social sciences (SPSS) version, 17.0 windows and differences in means were compared using the students' ttest and one-way analysis of variance (ANOVA). Error of probability or $\mathrm{P}<0.005$ was considered significant.

\section{Results}

In alloxan induced diabetic rats, there was marked hyperglycaemia (group C-E). The groups treated with an antihyperglycaemic agent and aqueous and dried okra extract showed steady decrease in glucose levels (table 1) significantly $(\mathrm{P}<0.05)$ in the first and second week. Diabetes

\section{Volume 4 Issue 11, November 2015}




\section{International Journal of Science and Research (IJSR) \\ ISSN (Online): 2319-7064}

Index Copernicus Value (2013): 6.14 | Impact Factor (2014): 5.611

was induced after the administration of alloxan. Alloxan induces a multiphasic blood glucose response when injected into an experimental animal and accompanied by corresponding inverse changes in the plasma insulin concentration, followed by sequential beta cell changes leading to necrotic cell death (Kliberet al., (1996). The first phase within few minutes after alloxan injection is the transient hypoglycaemic phase that lasts maximally for 30 minutes, which has been noted to be the result of transient stimulation of insulin secretionconfirmed by an increase of the plasma insulin concentration (Kliberet al., (1996). The underlying mechanism of the transient high insulin level may be attributed to a temporary rise in ATP availability due to inhibition of glucose phosphorylation through glucokinase inhibition (Wrenshawet al., 1996).

Table 1: Multiple Comparison of the Mean Glucose Levels (Mmol/L) of all the Groups in Day 3, Week 1 and Week 2.

\begin{tabular}{|c|c|c|c|}
\hline GROUPS & DAY 3 & WEEK 1 & WEEK 2 \\
\hline GROUP A & $4.86 \pm 0.21^{\mathrm{a}}$ & $4.81 \pm 0.28^{\mathrm{a}}$ & $4.57 \pm 0.32^{\mathrm{a}}$ \\
\hline GROUP B & $12.28 \pm 1.69^{\mathrm{c}}$ & $12.70 \pm 1.76^{\mathrm{c}}$ & $15.88 \pm 2.84^{\mathrm{d}}$ \\
\hline GROUP C & $16.76 \pm 1.10^{\mathrm{e}}$ & $14.93 \pm 1.20^{\mathrm{d}}$ & $10.15 \pm 3.04^{\mathrm{b}}$ \\
\hline GROUP D & $18.88 \pm 1.76^{\mathrm{e}}$ & $17.22 \pm 0.98^{\mathrm{e}}$ & $10.74 \pm 2.17^{\mathrm{b}}$ \\
\hline GROUP E & $11.26 \pm 1.81^{\mathrm{c}}$ & $10.45 \pm 0.98^{\mathrm{b}}$ & $7.69 \pm 1.81^{\mathrm{b}}$ \\
\hline
\end{tabular}

Values are mean \pm Standard Deviation. $n=5$. Within and across rows, same alphabets represent no significant difference in mean value while different alphabets represents a statistically significant difference in mean $(\mathrm{P} \leq 0.05)$.

In table 1, it was observed that the groups, which were induced with alloxan, had hyperglycaemia; of the induced groups, the ones that were treated with the standard antihyperglycaemic agents and aqueous and dried okra extract showed steady decrease in glucose levels over the two-week period. The diabetic controls however did not show any improvement but rather got increasingly hyperglycaemic.

Table 5 Multiple Comparison Tests For Different Periods In Group C, Group D, And Group E

\begin{tabular}{|c|c|c|c|c|}
\hline \multicolumn{2}{|c|}{ Comparison } & $\begin{array}{c}\text { Mean } \\
\text { Difference }\end{array}$ & T-Value & P-Value \\
\hline \multirow{4}{*}{ GROUP C } & DAY 3 VS WK 1 & -1.826 & 2.403 & $\mathrm{P}>0.05$ \\
\cline { 2 - 5 } & DAY 3 VS WK 2 & -6.608 & 3.689 & $\mathrm{P}<0.05$ \\
\cline { 2 - 5 } & WK 1 VS WK 2 & -4.782 & 3.556 & $\mathrm{P}<0.05$ \\
\hline & & & & \\
\hline GROUP D & DAY 3 VS WK 1 & -1.658 & 2.596 & $\mathrm{P}>0.05$ \\
\cline { 2 - 5 } & DAY 3 VS WK 2 & -8.140 & 5.563 & $\mathrm{P}<0.05$ \\
\cline { 2 - 5 } & WK 1 VS WK 2 & -6.482 & 5.178 & $\mathrm{P}<0.05$ \\
\hline & & & & \\
\hline \multirow{5}{*}{ GROUP E } & DAY 3 VS WK 1 & -0.810 & 0.719 & $\mathrm{P}>0.05$ \\
\cline { 2 - 5 } & DAY 3 VS WK 2 & -3.568 & 6.580 & $\mathrm{P}<0.05$ \\
\cline { 2 - 5 } & WK 1 VS WK 2 & -2.758 & 2.933 & $\mathrm{P}<0.05$ \\
\hline
\end{tabular}

$\mathrm{P}<0.05$ Represents A Significant Difference in Mean Values.

Table 5 is an illustration of a multiple comparison test for different periods in group $\mathrm{C}, \mathrm{D}$ and $\mathrm{E}$. The difference in mean observed in the table for all the groups $(\mathrm{C}, \mathrm{D}$ and $\mathrm{E})$ were negative indicating that there was a decrease in the glucose levels of the various groups over the two week period. This decrease was more pronounced between week 1 and week 2 than between Day 3 and week 1 .

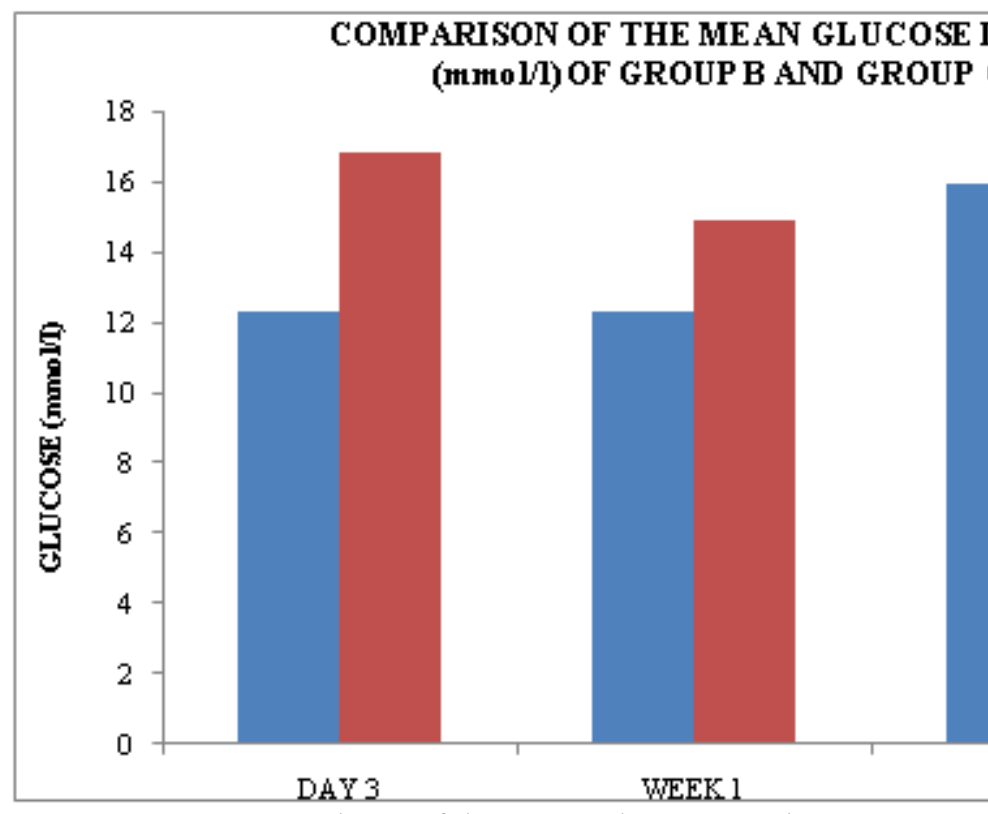

Figure 4.1: Comparisons of the Mean Glucose Levels (Mmol/L) of Group B And Group C in Day 3, Week 1, and Week 2.

\section{Discussion}

Plants are natural resources for human ailment. Folk medical uses are still implemented in this modern civilized era for the remedy of various complications. Abelmoschus esculentus revealed statistically significant hypoglycemic activity. Previous biological investigation showed that this plant contains secondary metabolites to reflect their hypoglycemic activity.

Aqueous extract and the dried powdered form of Abelmoschus esculentus were studied for their hypoglycemic effect and it was discovered that aqueous extract was showing maximum effect, using glibenclamide as standard.

There are many reports available to support the multiple mechanisms of anti diabetic plants to exert their blood glucose lowering effect, such as inhibition of carbohydrate metabolizing enzymes, enhancement of insulin sensitivity, regeneration of damaged pancreatic islets B-cells, and enhancement of insulin secretion and release (Moller and Nair, 2008). The aqueous extract and dried powder may exert blood glucose lowering activity possibly with the above mechanism(s) and the anti-hyperglycemic activity was comparable to that of glibenclamide.

In this study, the rats in group E had significantly lower glucose levels compared to that of group C. However, the difference in mean values between days 3 and week 2 of group $\mathrm{C}$ was significantly higher than that of group $\mathrm{E}$ meaning that Okra extract acts faster than the standard drug glibenclamide.

In the multiple comparison test for different periods in group $\mathrm{C}, \mathrm{D}$ and $\mathrm{E}$, the difference in mean observed in the table for all the 3 groups were negative indicating that there was a decrease in the glucose levels of the various group over the 2

\section{Volume 4 Issue 11, November 2015}




\section{International Journal of Science and Research (IJSR) \\ ISSN (Online): 2319-7064}

Index Copernicus Value (2013): 6.14 | Impact Factor (2014): 5.611

week period. This decrease was more pronounced between day 3 and week 1 meaning that the extracts became more available in the animal system in the second week than in the first week showing that its effects gets better with continuos use.

\section{Conclusion}

Diabetes is a widely spread disease. The present study was done with an objective to explore the biological use of Abelmoschus esculentus(okra), which is a commonly used plant throughout the world. In the present study, antihyperglycaemic effect of aqueous extract and powered form of Abelmoschus esculentus fruit was evaluated in alloxan induced diabetic rats. Okra is a natural product and it has anti-hyperglycemic activity and so the usage of the soaked okra extracts and powdered form of okra is not harmful to human health. In vivoexperiments with Wister rats shows a good result of anti-hyperglycemic activity, our experiment gives a preliminary information on this activity. Therefore the okra fruit can be used to treat/manage diabetes mellitus.

Future pharmacological investigations are suggested on the basis of the isolation principles and their mechanisms of anti-hyperglycemic effect.

\section{References}

[1] Aderigbe, A. O. Emudianughe, T. S. and Lawal, B. A. (1999). Antihyperglycaemic Effect of Magnifieraindica in Rats.Phytotherapeutic Research 13, 504-7.

[2] Ajabnoor, M. A. (1990), Effects of Aloes on Blood Glucose levels in Normal and Alloxan Diabetic mix. Journal, of Ethnopharmacology, 28,215-220.

[3] Assan, R., Penonne, C., Assan, D. and Matheron, S. (1995). Pentamidine induced derangement of glucose homestasis. Diabetes Care, 18, 47 - 55 .

[4] Bakhru, H. K. (2000). Healing through Natural Foods. Jaico Publishing

[5] Balch, J. F. and Balch, P.A (2000). Prescription for Nutritional Healing. A very Penguim Putnam Corporation. New York, Pp 267-270.

[6] Beretta, A. (2012). Prevalence of Diabetes Impaired Fasting Glucose and Impaired Glucose Tolerance in U.S Adults. The Third National Health and Nutrition Examination Survey 1988 - 1994. Diabetes Care, 21(4), $518-524$.

[7] Bhowmilk, A., Khan L. A. Akther M. and Rokeya, B. (2009). Studies on the anti-Diabetic effects of Magniferaindica stem, barks and leaves on diabetic Type 1 and Type 2 Diabetic rats. Banglandesh Journal of Pharmacology, 4, 110-114

[8] Boussageon R., Benjan-Angoutiant, T., Saadotian-Etahi M. Latout S., Beregeonmeau C., Kassai B., Erpeldinger S.and Wright J. M. (2009). Effect of Intensive Glucose. Lowering Treatment on mortality Cardiovascular Death and Microvascular events in type 2 Diabetics, MetaAnalysis of Randomised Controlled Trials, 343, 4169.

[9] Bruns, D. E. (2000). Interpretation of HbA1c test: Why it matters.
[10]Bryne, M. M. and Feely, J. (2003). Altered Insulin Secretary Response to Glucose in Diabetic and Non Diabetic Subjects with Mutations in Diabetes Susceptibility Gene. Diabetes Care, 45, 1503 - 10.

[11] Campbell, J and Carlson M. G. (2003). Impact of Obesity on Insulin Action in NIDDM.Diabetes Care, $42,405-410$.

[12] Carvalho, C. C., Cruz, P. A., Xavier L. (2011) Antibacterial properties of the extract of Abelmoschus esculentus. Biotechnology and Bioprocess Engineering.16(5). $971-77$.

[13] Chopra, R.N., Nayor S. L., Chopra I. C., (1956) Glossary of Indian Medical Plants. Council of Industrial and Scientific Research Pp. 1 - 13.Clinical Chemistry, $50,400-450$.

[14] Das J., Vasan V and Sol, P. C. (2003), Taurene Exerts Hypoglycaemic Effect in Allosan Induced Diabetic Rats, Improves Insulin Mediated Glucose Transport Signaling Pathway in Heart and Ameliorates Cardiac

[15] Oxidative Stress and Apoptosis. Toxicological Applications of Pharmacology,258, 296-308.

[16] Ichinose, K., Kawasaki, E. and Eguchi, K. (2007). Recent Advancement of Understanding Pathogenesis of Type I Diabetes and Potential Relevance to Diabetes Nephropathy. American Journal of Nephrology, 27 (6), $554-564$

[17] Khomsung P; Thongiaroenbuangan W; Pakdeenarong N, Suttajit M., Chantitratikul P. (2010). Anti-oxidative activities and phenolic content of extracts from okra (Abelmoschus esculentus).Russian Journal of Biological Science.5, 310 - 13.

[18]Kliber, A., Skuldebeki, T. and Chichlowska J., (1996).Stimulation and subsequent inhibition of Insulin Release from Imide Performed Rat Pancrease.Journal of Physiological Pharmacology, 47,321 - 8.

[19] Macedo, C. S., Capellettism, M.C, Padovani, C. R. and Spadella, C.T. (2002). Role of Metabolic control on Diabetic Nephropathy. Acta Bras, 17(6), 37 - 5.

[20]Rajaopal, K. and Sasrikala, K. (2008) Anti Hyperglycaemic and antihyperlipidaemic effect of Nymphaeastellata in allozan induced Diabetic rats. Singaporean Medical Journal; 49:137-147

[21]Rees, D. A. andAlcolado, J. C. (2005). Insulin Dependent Diabetes Mellitus induced by subdiabetogenic doses of Streptozotocin: Obligatory role of Cell-mediated Autoimmune process. National Academic Science, 77 (10).

[22] Yeh, G. Y; Eisenberg, D. M; Kaptchuk, N. M and Philips T. J. (2003).Systemic Review of Herbs and Dietary Supplements for glycaemic control in Diabetes.Diabetes Care, 26, 1277 - 94.

[23] World Health Organisation (2011). Definition, Diagnosis and Classification of Diabetes Mellitus and its Complication part 1: Diagnosis and Classification of Diabetes Mellitus. World Health Organisation Press, $10-22$. 